\section{New fears at Hanford}

\section{Boston}

The Hanford Nuclear Reservation in Washington state is in trouble again, with the release last week of a report from a US Department of Energy (DOE) advisory panel saying that gases trapped within some of the millions of gallons of highly radioactive wastes stored in underground tanks at the facility could explode.

Government documents unearthed by congressional staff show that DOE contractors knew of the existence of flammable hydrogen gas in at least one tank at Hanford for 13 years, but did not notify higher authorities or attempt to remove the danger until this spring. Warnings of the potential danger of explosion at underground tanks at Hanford and other nuclear production facilities have occasionally surfaced over the past few years.

But no earlier warnings have combined the urgency and authority of the report issued last week by the Energy Department's advisory committee on Nuclear Facility Safety, chaired by John F. Ahearne, former head of the US Nuclear Regulatory Commission.

In a letter sent to Energy Secretary James Watkins last month, before the public release of the report, Ahearne's committee described the tanks as presenting "a serious situation, if not an imminent hazard". Furthermore, the committee wrote, the consequences of an explosion could be grave, owing to "the magnitude of the radioactive inventory available for dispersal".

The problem at Hanford is that a crystallized crust has developed on top of the liquid waste in some of the storage tanks. The crust, which can be as much as two or three feet thick, is believed to have been

\section{FRENCH UNIVERSITIES}

\section{Open season}

\section{Paris}

THE French education minister, Lionel Jospin, is considering setting up a new university, with courses taught through correspondence and the media, on the lines of the successful British Open University which was founded in 1969.

Jospin is currently studying a report by Oliver Duhamel, a lecturer at the University of Paris I, which, while inevitably using the British experiment as a model, nevertheless envisages a less centralized structure. Duhamel proposes a regional organization, linked to state universities and higher education centres, which will also build on existing facilities for learning-at-adistance. There has been no mention of the amount of time and money needed to establish the venture, but Jospin promised initial experiments in 1992. Peter Coles Soviet Union. caused by chemicals that were added in the late 1950 s and 1960 s to newly produced liquid wastes at Hanford in order to reduce their volume. Hydrogen gas, which is known to build up in the liquid waste, is now trapped underneath the hardened crust and, according to the report, could be detonated by heat generated inside the tanks or by a spark or shock from outside. The chemical explosion could spread long-lived radioisotopes, including caesium-137 and strontium-90, into the surroundings.

Ironically, Hanford's tank farm was intended to provide only temporary storage for the highly radioactive liquid wastes generated from the processing of plutonium for use in nuclear weapons. Construction began in the 1940s and continued through the 1950 s and 1960 s as the Hanford facility increased its output of plutonium. But despite the passage of over 40 years, no permanent solution has been found to the disposal problem posed by the liquid wastes. Many of the tanks have leaked.

Dealing with the problems of the Hanford tanks is made more difficult by the lack of knowledge of what is happening inside them. What is certain is that hydrogen trapped in some of the tanks frequently causes so-called 'tank belches' in which the tank's crust moves upwards, sometimes as much as a foot, as it vents the trapped gas. Information released by Senator John Glenn, who chaired congressional hearings on the problem last week, shows that at least three "major steam explosions" have occurred at Hanford's tanks. One explosion, in 1965, lifted a tank six feet off its underground foundation and sent a geyser of radioactive steam 50 feet high into the air.

At the hearing, Glenn said that there is a risk of an explosion comparable to one that occurred in the Ural Mountains of the Soviet Union in 1957, forcing the evacuation of 10,000 people.

DOE officials, however, maintain that the two situations are different, in part because the temperature of Hanford's wastes are believed to be far lower than that which caused the explosion in the

Privately, DOE may be more concerned about the situation than it says. An inside congressional source said over a month ago that DOE was "frantic" about the situation. A DOE official confirmed that one tank at Hanford has been declared off limits to Hanford workers for over a year because of fears that activity could touch off an explosion. One tank, known as 101-SY, is almost continuously "belching" hydrogen, according to the official, confounding scientific explanations of the phenomenon. Seth Shulman

\section{The long and winding road}

\section{San Francisco}

Cetus Corporation stumbled on its long road to profitability last week when a US Food and Drug Administration (FDA) reg. ulatory panel refused to grant marketing approval of its most important product, interleukin-2. The surprise announcement sent Cetus stock plummeting, but analysts believe the company is secure enough to weather a delay of several months or more without needing to shed any of its workforce. Approval may be delayed for three months to a year.

Cetus, which is based in Emeryville in California, had high hopes for its first, and only, therapeutic biotechnology product in the near term. It retains however a measure of security from its other endeavors: the three drugs that are in clinical trials, the marketing of generic cancer drugs and the diagnostic application of the company's important polymerase chain reaction technology.

The US FDA's Biological Response Modifiers Advisory Committee asked Cetus to reanalyse some of its data on interleukin-2, which the company planned to offer for the treatment of kidney cancer. Officials of the company hope to meet with the FDA later this month to discuss the recommendation and to determine whether additional testing of the drug will also be required.

Cetus found that the genetically engineered drug caused partial remission in approximately 20 per cent of the patients treated, but the Committee raised concerns over clinical testing methods and side effects. The Biological Response Modifiers Advisory Committee is a new group comprised of nine immunologists who evaluate safety and efficacy data on new drugs and make recommendations to the FDA. Last week, the panel also asked Immunex Corporation of Seattle, Washington, for more study data on the drug GM-CSF (granulocyte macrophage colony stimulating factor) as a treatment for bone-marrow transplant rejection before making its recommendation to the FDA on market approval.

Cetus's President and Chief Executive Officer, Robert A. Fildes, was surprised and disappointed by the FDA decision. "We think we have shown over the past five years that this does bring benefit to a substantial number of people," he said. The drug, which Cetus calls Proleukin, is already approved in nine European countries for the treatment of kidney cancer, and it is in clinical trials in Europe and the United States for treatment of other disorders; Cetus plans to request approval soon in Europe to market Proleukin for the treatment of skin cancer.

Elizabeth Schaefer 